내시경적 접근이 어려운 담도 결석과 담도 폐쇄 환자에서 경피간담도 배액술과 경피적 풍선확장술: 단일 기관의 환자 21 명에 대한 증례들

홍익병원 소화기내과

김 근 · 김정권 · 지주연 · 김시호 · 박지환 · 경규천 · 안효동 · 김민정 · 이종성

\title{
Percutaneous Transhepatic Biliary Drainage and Percutaneous Balloon Dilatation for Patients with Biliary Duct Stones and Biliary Obstruction in Whom an Endoscopic Approach Is Difficult to Use: Case Series of 21 Patients at a Single Institution
}

Geun Kim, Jung Kwon Kim, Ju Yeon Jl, Si Ho Kim, Ji Hwan Park, Gyu Cheon Kyung, Hyo Dong An, Min Jung Kim, Jong Seong Lee

Division of Gastroenterology, Department of Internal Medicine, Hongik Hospital, Seoul, Korea

Background/Aim: The aim of this study was to evaluate the stability and simplicity of papillary balloon dilatation by retrospectively analyzing the results of performing concurrent papillary balloon dilatation in conjunction with percutaneous transhepatic biliary drainage (PTBD) in the patients with biliary obstruction due to common bile duct stones or a tumor who were difficult to treat with an endoscopic approach.

Methods: We retrospectively analyzed a total of 21 patients who were treated through a percutaneous transhepatic biliary approach after they were diagnosed with biliary obstruction due to a tumor and biliary stones in a single medical institution for four years from 2012 to 2015.

Results: Sixteen out of 21 patients (76.2\%) underwent percutaneous transhepatic biliary drainage and papillary balloon dilatation. For 5 patients (23.8\%) in whom it was difficult to perform the procedure simultaneously due to the patient's poor overall condition such as pancreatitis and septic shock, papillary balloon dilatation was performed 5-8 days after biliary drainage. Nineteen of 21 patients (90.5\%) were successfully treated by a single procedure without residual stones or restenosis, but in two patients, stones were removed two times and three times.

Conclusions: The use of a percutaneous transhepatic biliary approach to patients in whom endoscopy cannot be performed is considered safe and effective. In addition, unless the procedure is specifically contraindicated, the use of papillary balloon dilatation performed simultaneously with PTBD can reduce patient inconvenience and procedure frequency.

Korean J Pancreas Biliary Tract 2017;22(3):134-140

Keywords: Drainage, Gallstones, Dilatation
Received Mar. 8, 2017

Revised May. 4, 2017

Accepted May. 29, 2017

Corresponding author : Jeong Kwon Kim Division of Gastroenterology, Department of Internal Medicine, Hongik Hospital, 22 Deungchon-ro, Yangcheon-gu, Seoul 07966, Korea

Tel. +82-2-2600-1525 Fax. +82-2-2600-4605

E-mail; kimjkclinic@hanmail.net 


\section{서 론}

총담도 결석 혹은 종양으로 인한 담도 폐쇄는 황달, 발열, 상 복부 통증, 패혈증 등을 유발할 수 있어 조기에 적절한 치료가 필요하다. 1974년 Kawai 등에 의해 처음 시작된 이후 내시경 역행성 담췌관조영술(endoscopic retrograde cholangiopancreatography, ERCP)을 이용하여 접근하는 시술이 현재까지 가장 보편적인 치료 경로로 이용되고 있다. 그러나 환자가 billroth II 수술, Roux-en-Y 문합술을 시행시 성공률이 각각 $92 \%,{ }^{2} 67 \%{ }^{3}$ 로 정상해부학적 구조를 가진 환자에 비해 낮았으 며, 유두부 주위 게실(periampullary diverticulum)이 있는 경 우에도 $62.4 \%$ 의 성공률을 보였으며 특히 intradiverticular papilla (IDP)에서는 $38.1 \%$ 로 성공률이 더 낮았다. 또한 환자가 billroth II 수술, Roux-en-Y 문합술 환자에서 시술시 발생하는 합병증 발생률도 각각 $8-17 \%,{ }^{5,6} 12 \%{ }^{3}$ 로 정상 환자에 비해 높 게 나왔다. 그 밖에 종양으로 인한 담도 폐쇄가 심하거나, 패혈 증 등 전신상태가 좋지 않은 경우 내시경 접근 자체가 어려운 경우도 있다.

이런 환자들에서 $\mathrm{ERCP}$ 를 대체하는 방법으로 경피경간적 담도접근(percutaneous transhepatic biliary approach)이 많이 이용되고 있다. ${ }^{7}$ 경피적 경로를 통해 풍선카테터를 삽입한 후 유두부를 확장시키는 유두부풍선확장술(papillary balloon dilatation, $\mathrm{PBD}$ ) 후, 결석을 십이지장 쪽으로 밀어서 제거하게 된다. 담도 폐쇄 환자에서도 경피적 경로를 통해 stent를 삽입 하여 담도 배액이 원활하도록 하는 시술이 내시경적 접근이 어려운 환자들에 있어 유용하다. ${ }^{8,9}$

이러한 이유로 점차 이 시술의 이용이 늘어나고 있지만, 현 재 다른 연구에서는 경피경간 담도배액술(percutaneous transhepatic biliary drainage, PTBD)을 시행한 후 평균 6-7일 후에 PTBD 경로를 이용한 시술을 진행하고 있다. ${ }^{8}$ 하지만 본 연구 에서는 시술 횟수의 감소 및 시간 단축을 통해 환자의 통증 감 소 및 입원 기간 단축을 예상하였다. García-García와 Lan$\mathrm{ciego}^{8}$ 에서도 몇몇 환자에서 성공적으로 시행한 바, 4 년간 단 일기관에서 환자의 상태에 따라 $\mathrm{PTBD}$ 와 동시에 $\mathrm{PBD}$ 를 진행 한 결과를 후향적으로 분석하여 시술의 성공률과 합병증 발생 률 대해 알아보고자 하였다.

\section{방 법}

이번 연구는 환자의 의무기록을 통한 후향적 분석으로 진행
되었다. 2012년부터 2015년까지 4년간 단일기관에서 종양 및 담도 결석으로 인한 담도 폐쇄를 진단받고 입원한 환자 중에 서 sepsis, pneumonia 동반 및 dementia로 환자의 협조가 어려 워 내시경적 접근이 불가능하다고 판단된 환자 8명과 Billroth II 문합술을 하였거나 유두부 주위 게실이 있거나 종양으로 인 한 담도 폐쇄가 있어 내시경적 접근을 시도하였으나 실패한 13 명을 대상으로 진행되었다. 모든 환자는 우상 복부 통증, 황 달, 발열 등의 담도 폐쇄 증상을 호소하여 내원하였고, 혈액 검 사와 복부 전산화단층촬영을 시행하였으며, 담도염 치료를 위 해 광범위 항생제를 사용하였다.

전체 21 명 중 염증수치가 정상소견 및 증상이 경미하고 생체 징후가 안정적이었던 16 명의 환자에서 $\mathrm{PTBD}$ 와 동시에 $\mathrm{PBD}$ 를 시행하였다. PBD 후 balloon catheter를 이용하여 결석을 십 이지장으로 밀어내거나(Fig. 1) 경피경관담관조영술(percutaneous transhepatic cholangiogram, PTC)을 시행한 후 좁아진 부위에 stent와 풍선확장술을 이용하여 담도 배액을 시행하였 다(Fig. 2). 패혈성 쇼크 등 American Society of Anesthesiologists (ASA) IV에 해당하는 환자 5 명에서는 증상 경감을 위해 PTBD 시행 5-8일 후에 시술을 진행하였다. PTBD 후 PTC를 시행하여 담도의 구조, 결석의 위치, 크기, 개수, 협착 정도를 미리 확인하였다.

담도 결석 시술시, 초음파 투시 하에 21-G 시바(Chiba needle; M.I.Tech., Seoul, Korea)로 천자하였다. 경피경간 통로를 통하여 0.035-inch 유도 철사(stiff guidewire; Radifocus ${ }^{\circledR}$ Guide wire M; Terumo, Tokyo, Japan)를 간 외 담관을 지나 십이지장 유두부를 통과시켰다. 그 후 $8 \mathrm{Fr}$ 유도관(Accusheath, SUNGWONMEDICAL, Cheongju, Korea)으로 교체 하였다. 그 후 $10 \mathrm{~mm} \times 4 \mathrm{~cm}$ 혈관 성형용 풍선 카테터(UltraThin $^{\mathrm{TM}}$ Diamond ${ }^{\mathrm{TM}}$; Boston Scientific, Marlborough, MA, USA)를 guide-wire를 통해 십이지장 유두부를 통과시킨 후 $\mathrm{PBD}$ 를 4-6기압으로 30-60초간 2회씩 시행하였다. 유두부를 확장시킨 후 balloon catheter를 그대로 유두부를 통과시켜 음 압으로 결석이 따라 나오게 하거나 balloon catheter를 결석의 뒤로 이동시켜 결석을 십이지장 안으로 밀어내었다. 결석의 크기가 $15 \mathrm{~mm}$ 를 넘는 경우에는 바스켓 카테터(Wittich Nitinol Stone Basket; Cook, Bloomington, IN, USA)를 통과시켜 부분 쇄석술을 시행한 후 결석 제거술을 시행하였다. 시술 후, PTBD 카테터로 교체하고 2-3일 후 추적 담관조영술을 시행 하여 잔류 결석 유무 및 담도 폐쇄 유무를 확인하였다. 잔류 결 석이 남아있는 경우에는 위의 시술을 한 번 더 반복한 후 2-3 

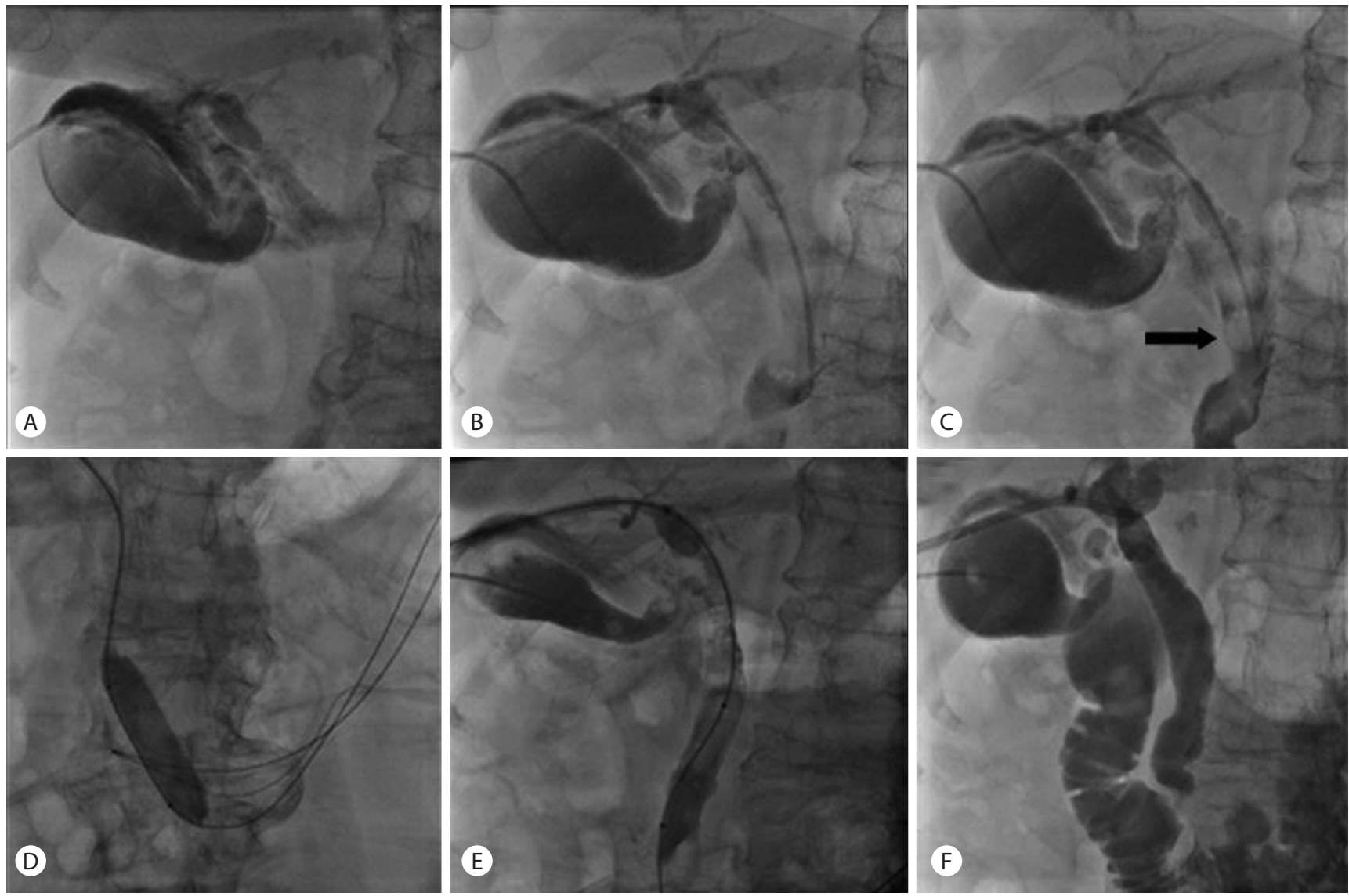

Fig. 1. The percutaneous transhepatic biliary drainage and papillary balloon dilatation method of stone removal using a balloon catheter in an 83 -yearold patient with one extrahepatic bile duct stone. (A) Percutaneous transhepatic gallbladder drainage was performed. (B) A 0.035-inch stiff guidewire was passed to the duodenum. (C) Stones was seen in the extrahepatic bile duct (black arrow). (D) The ampullary sphincter was dilated using a balloon. (E) The stone was pushed into the duodenum using a balloon catheter. (F) The stone was no longer seen in the biliary tract, but was now seen in the duodenum.

일 후 담관조영술을 재시행하여 잔류 결석 유무를 확인하였다.

종양으로 인한 담도 협착시, 결석과 마찬가지로 유도 철사 를 십이지장까지 위치시키고, $5 \mathrm{~cm}$ 정도의 금속 스텐트(Niti-S stents; Taewoong Medical Corporation, Seoul, Korea)를 유두 부 밖 $1 \mathrm{~cm}$ 정도 근처에 위치시킨 후, 금속 스텐트를 확장시켜 제자리에 위치하였다. 좁아진 부위의 원활한 통과를 위해 balloon catheter를 이용하여 확장시켜 넓어진 담도를 확인한 후 PTBD catheter를 스텐트 상부에 위치시킨 후 시술 2-3일 후에 협착 유무를 확인하였다.

잔류 결석이 없고, 스텐트를 삽입한 후 시행한 담관배액술 에서 스텐트가 잘 유지되며, 조영제가 막힘 없이 십이지장으 로 잘 통과하고, 재시술을 시행하였더라도 결석을 제거한 경 우 성공하였다고 판단하였다. 결석의 크기는 가장 큰 결석의 장경으로 측정하였다. 임상증상 및 amylase, lipase를 포함한
혈액 검사를 시행하여 합병증 발생 유무에 대해 확인하였다. 입원 기간 및 ERCP 시행 유무와 시행하였다면 실패한 이유를 조사하였고, $\mathrm{PTBD}$ 와 $\mathrm{PBD}$ 의 동시 진행 여부 및 진행하지 못 한 경우, 그 이유에 대해 조사하였다.

\section{결 과}

경피적 경로를 통한 $\mathrm{PBD}$ 시술을 시행한 21 명의 치료 결과 에 대해 Table 1에 정리하였다. 남자가 10명(47.6\%), 여자가 11 명(52.4\%)이었으며 환자들의 평균 연령은 78.4세(46-97세) 였다. 전체 환자 중 sepsis, pneumonia 동반 및 dementia로 환 자의 협조가 어려워 내시경적 접근이 불가능하다고 판단된 환 자가 8 명 $(38.1 \%)$ 이었으며 그중 한 명은 sepsis 및 Billroth II 문 합술 과거력이 있어 내시경적 접근을 하지 않았다. 그 외 Bill- 

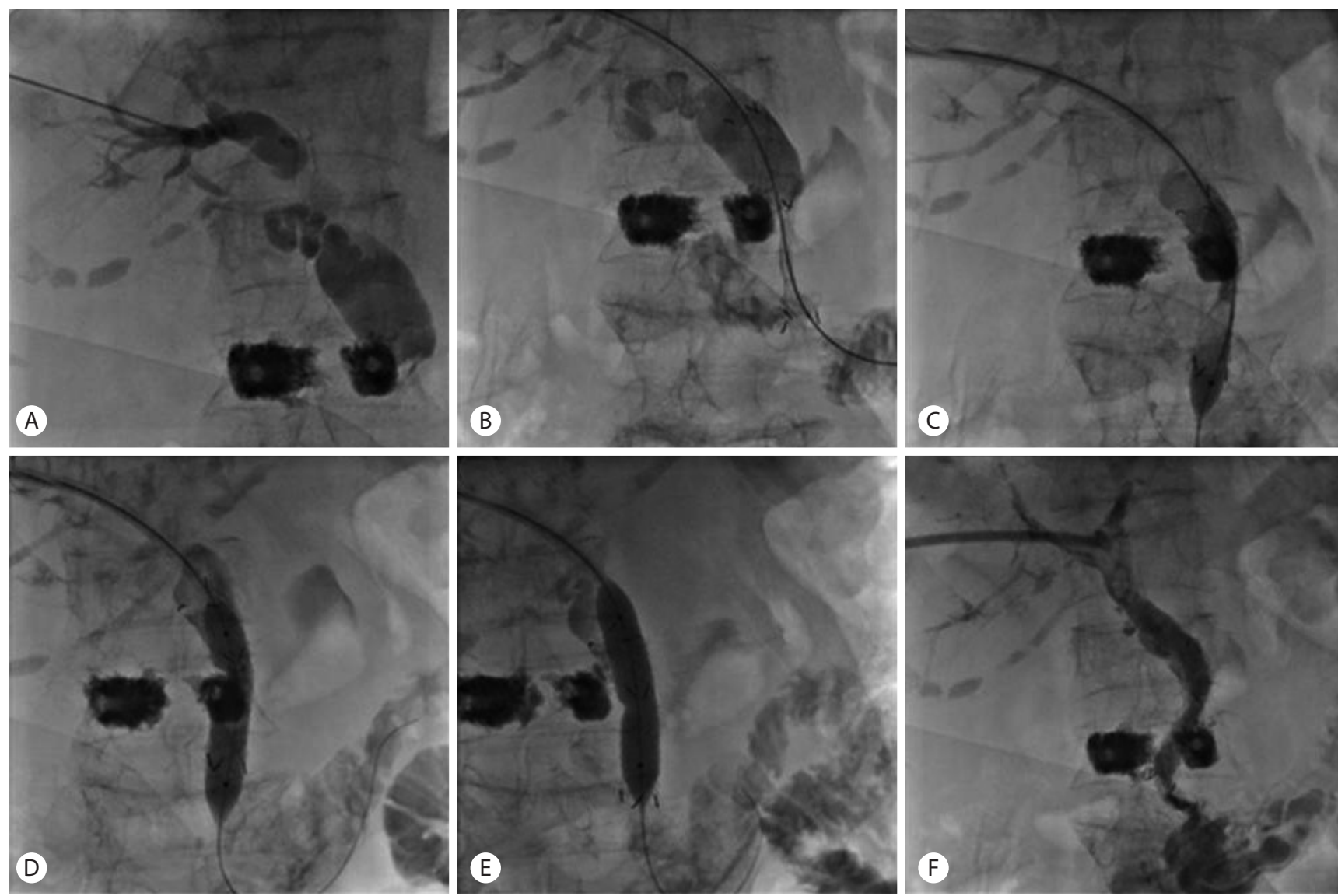

Fig. 2. The stent insertion using a balloon catheter in a 89-year-old patient with pancreatic cancer. (A, B) A 0.035-inch stiff guidewire was passed to the duodenum. (C, D) The ampullary sphincter was diated using a 10-mm balloon. (E) The stent was inserted into distal Common bile duct. (10 mm, $6 \mathrm{~cm}$ in length) (F) Good flow passage was seen.

roth II 문합술을 한 환자 1명(4.8\%), Roux-en-Y 수술을 받은 환자 2명 (9.5\%), juxtapapillary diverticulum이 있는 환자 4 명 (19\%), 종양으로 인한 담도 폐쇄 3명(14.3\%), 유두부가 작아 실패한 3명 $(14.3 \%)$ 을 포함해 내시경적 접근을 시도하였으나 실패한 환자가 13 명 $(61.9 \%)$ 이었다.

결석이 있는 사람 18 명을 대상으로 할 때 8 명 $(44.4 \%)$ 은 결 석이 한 개, 5 명 $(28 \%)$ 은 두 개 그리고 남은 5 명 $(28 \%)$ 은 결석 이 세 개 이상이었으며 결석의 크기는 직경이 평균 $14.3 \mathrm{~mm}$ (6.8-27 mm)였다. 세 명 $(14.3 \%)$ 은 입원 당일 PTBD 혹은 경피 경간담낭배액술(percutaneous transhepatic gallbladder drainage, PTGBD)을 시행하였고, 4명(19\%)은 하루 후, 6명(28.6\%) 은 이틀 후, 3 명(14.3\%)은 삼일 후, 나머지 5 명은 각각 입원 4일, 7일, 8일, 9일, 11 일 후 PTBD 혹은 PTGBD를 통해 배액술을 진 행하였다. 21 명 중 환자의 생체징후가 안정적이며 증상이 심 하지 않은 16 명(76.2\%)의 환자에서 $\mathrm{PTBD}$ 와 동시에 $\mathrm{PBD}$ 를 진행하였고, 5 명 $(23.8 \%)$ 은 높은 염증수치 및 발열, 복통 등 증
상이 심하여 이차적인 담도염 예방을 위해 $\mathrm{PTBD}$ 로 증상 완화 후 각각 5-8일 후에 시술을 진행하였다. 21 명의 환자 중 19 명 (90.5\%)에서 잔류 결석이나 재협착 없이 한 차례만의 시술로 성공하였다. 나머지 두 명은 각각 2 회, 3 회 $\mathrm{PBD}$ 를 시행한 후 결석 제거에 성공하였다. 결석 크기가 $15 \mathrm{~mm}$ 보다 큰 4 명 (19\%)은 바스켓을 이용한 부분 쇄석술을 진행하였다. 시술에 성공한 21명의 환자 모두 2-3일 후에 PTC를 재시행하여 잔류 결석 유무 및 조영제를 통해 담도 폐쇄가 없음을 확인한 후 대 부분 일주일 후에 PTBD catheter를 제거하였다. 모든 환자에 서 복통을 호소하였고, 5 명 $23.8 \%)$ 에서 일시적인 아밀라아제 상승 소견을 보였으며 리파아제는 정상수치를 유지하였고, 아밀라아제 또한 수일내 모두 정상수치로 회복되었다. 주요 합병증으로 한 명 $(4.8 \%)$ 은 $\mathrm{PTBD}$ 부위에 농양이 관찰되어 percutaneous abscess drainage 삽입 및 항생제 투여 후 증상이 호전되었으며, 한 명(4.8\%)은 성공적으로 담석 제거 후에도 패혈증이 지속되었으며 다발성 장기부전 후 결국 사망하였다. 


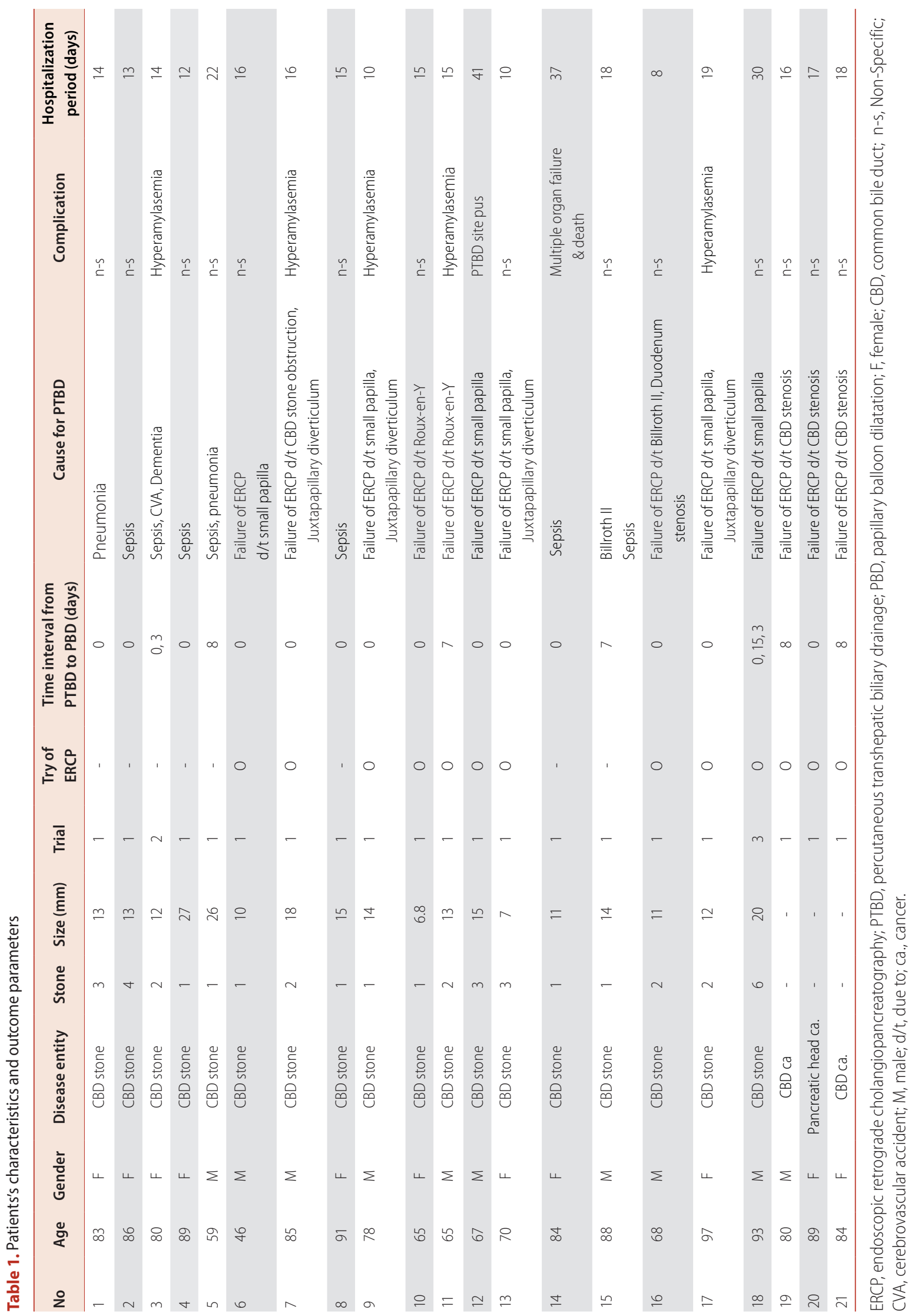


시술 중 출혈 및 천공은 한 차례도 발생하지 않았다. 21 명의 환 자 중 추적관찰이 되지 않거나 연락이 되지 않는 6 명을 제외한 15 명의 환자들에 대해 평균 2 개월 동안 추적관찰하였고 재발 이 나타나지 않음을 확인하였다. 환자들의 평균 입원 기간은 17.9 일(8-41일)이었으며 시술 후 입원 기간은 12.8 일(6-36일) 이었다. $\mathrm{PTBD}$ 와 동시에 $\mathrm{PBD}$ 를 동시에 진행한 군에서 입원 기간은 17.9일이었으며, PTBD 후 5-8일 후에 PBD를 진행한 군은 17.8 일로 큰 차이는 없었다.

\section{고 찰}

원위부 담도 협착은 췌장암, 담도암, 담낭암 혹은 담도 결석 에 의해 흔하게 유발되며 담도염, 패혈증 등을 유발한다. 이러 한 담도 협착을 치료하기 위해 담도 결석의 경우 결석을 제거 하거나 악성 담도 협착시 증상의 완화 치료 또는 수술 전 일시 적인 감압을 위한 스텐트 삽입을 하게 된다. 이러한 치료를 위 한 접근법으로는 내시경을 이용한 접근이 많이 이용되지만 Billroth II 수술을 하였거나, Roux-en-Y 문합술을 하였거나 IDP 경우, 시술 성공률이 각각 $92 \%, 67 \%, 38.1 \%$ 로 정상 해부 학적 구조를 가진 환자에 비하여 성공률이 낮고 합병증 발생 률 또한 높게 나온다고 보고되고 있다. ${ }^{2-6}$

이러한 경우 경피경간 경로를 통해 결석 제거 혹은 스텐트 삽입을 시행하게 된다. ${ }^{10}$ 경피적 경로를 통한 접근은 Mondet ${ }^{11}$ 에 의해 처음으로 보고되었고, 1979년 Perez 등 ${ }^{12}$ 과 Dotter 등 $^{13}$ 에 의해 경피경간 결석 제거 및 십이지장으로 결석을 밀어내는 방법이 보고가 된 이후 풍선확장술 및 혈관 삽입기의 도입 ${ }^{10}$ 등 많은 발전이 있어왔다. 경피적 접근은 간내 담석의 제거에도 접근 경로가 짧다는 장점이 있다. ${ }^{14} 212$ 명을 대상으로 GarcíaGarcía와 Lanciego ${ }^{8}$ 의 연구에서도 경피적 접근을 통한 technical success가 $93 \%$ 높았으며 mortality rate 및 complication도 $\mathrm{ERCP}$ 를 통한 접근에 비해 적었다. 또한 담즙의 방향과 같은 방향으로 결석을 밀어내기 때문에 각도를 유지하기도 용이하 며, 유두부의 중앙에 적절히 풍선을 위치시키기에도 수월하였 으며, expulsion maneuver를 여러 번 시행하는 것이 가능하였 다. ${ }^{8}$ 또한 결석의 크기가 $15 \mathrm{~mm}$ 이상으로 큰 환자를 대상으로 도 basket을 이용하여 안전하게 결석 제거가 가능함을 확인하 였다.

Occlusion balloon을 이용하였던 다른 연구 ${ }^{10}$ 와는 다르게 dilatation balloon만을 이용하여 결석을 제거하였다. 그리하여 occlusion balloon catheter로 교체하기 위해 근위부 쪽으로 catheter를 빼다가 결석이 같이 간담도 내로 올라오는 것을 예 방할 수 있었다. 모든 환자에서 성공적으로 담도내 결석 제거 및 stent를 삽입하였으나, 복통 및 경미한 아밀라아제 상승 소 견이 관찰되었으며 치명적 합병증 또한 PTBD 삽입 부위의 농 양 및 다발성 장기부전으로 인한 사망이 한 차례씩 관찰되었 다. 환자들의 평균 입원 기간은 17.9 일(8-41일)이었으며 시술 후 입원 기간은 12.8일(6-36일)이었다. 타 논문에서 시술 후 입 원 기간 5.5일(1-40일) 및 시술 전 평균 13.5일(2-45일) 입원하 여 큰 차이를 보이지는 않았다. ${ }^{15}$

본 연구에서는 시술 횟수의 단축을 통해 환자의 증상 호전 및 입원 기간 단축, 비용절감, 환자의 불편을 감소시킬 것이라 고 예상하였다. 앞선 논문들에서 담즙의 배출을 통해 담도염 을 예방하고자 시술 2 일 전 길게는 45 일 전에 미리 $\mathrm{PTBD}$ 를 시 행하고 있는 것에 비해 ${ }^{8}$ 본 연구에서는 패혈증 등 ASA grade IV에 해당하여 합병증의 가능성이 높은 환자를 제외한 대부 분의 환자에서 $\mathrm{PTBD}$ 와 동시에 $\mathrm{PBD}$ 를 통한 시술을 진행하였 고, 대부분의 환자들에서 불편을 빠르게 해소하였다. 하지만 $\mathrm{PTBD}$ 와 동시에 $\mathrm{PBD}$ 를 동시에 진행한 군에서 입원 기간은 17.9일이었으며, PTBD 후 5-8일 후에 PBD를 진행한 군은 17.8 일로 큰 차이가 없었다. 합병증 발생률 또한 $\mathrm{PTBD}$ 와 $\mathrm{PBD}$ 를 동시에 진행한 군에서 경도의 amylase 상승을 포함하여 16 명 중 7명에서 발생하였으며, PTBD 후 5-8일 후에 PBD를 진 행한 군에서는 다섯 명 중 한 명에서 amylase 상승을 보여 두 군에서 차이가 크지 않았다. 이 연구의 한계점으로는 첫째 단 일기관에서 후향적으로 연구가 진행되어 선택 편향이 있을 수 있다는 점이다. 둘째, 대상 환자가 적어 이 시술에 대한 안전성 을 일반화하기 어렵다는 점이다.

결론적으로 Billroth II 수술이나 Roux-en-Y 문합술을 한 경 우, IDP 등 해부학적 변형이 있는 경우, 내시경적 접근이 어려 울 수 있으며, 이런 환자들에 대한 경피적 경로를 통한 시술은 보다 안전하고 높은 성공률을 보인다. 또한 환자의 생체징후 가 안정적이고, 염증수치가 낮으며, 증상이 경미할 경우, $\mathrm{PTBD}$ 와 동시에 $\mathrm{PBD}$ 후 결석 제거 혹은 스텐트 삽입을 진행하 는 방법은 환자의 고통 및 비용 절감에 효과적이라고 할 수 있 으며 추후 이 시술에 대한 광범위한 연구가 진행되길 바란다.

\section{요 약}

배경/목적: 총담도 결석 혹은 종양으로 인한 담도 폐쇄에서 내시경적 접근이 어려운 경우, 경피경간담도배액술과 동시에 
유두부 풍선확장술을 진행한 결과를 후향적으로 분석하여 시 술의 안정성 및 간편화에 대해 알아보고자 하였다.

방법: 2012년부터 2015년까지 4년간 단일기관에서 종양 및 담도 결석으로 인한 담도 폐쇄를 진단받고 경피적 접근을 통 해 시술한 환자 21 명을 후향적으로 조사하였다.

결과: 21 명 중 16 명 $(76.2 \%)$ 의 환자에서 경피경간담도배액 술과 동시에 유두부 풍선확장술을 진행하였고, 나머지 5명 (23.8\%)은 담도배액술 5-8일 후에 시술을 진행하였다. 21 명의 환자 중 19 명 $(90.5 \%)$ 에서 잔류 결석이나 재협착 없이 한 차례 만의 시술로 성공하였다. 나머지 두 명은 각각 2 회, 3 회 $\mathrm{PBD}$ 시행 후 결석 제거에 성공하였다.

결론: 내시경을 시행하지 못하는 환자들에 대한 경피적 접 근을 통한 시술은 안전하고 효과적이라고 할 수 있으며, 특별 한 금기가 되지 않는 한 경피경간담도배액술과 동시에 시행하 는 유두부 풍선확장술은 환자의 불편 및 시술 횟수를 감소시 킬 수 있다.

국문 색인: 배액, 담석, 확장

\section{Conflicts of Interest}

The authors have no conflicts to disclose.

\section{REFERENCES}

1. Kawai K, Akasaka Y, Murakami K, Tada M, Koil Y. Endoscopic sphincterotomy of the ampulla of Vater. Gastrointest Endosc 1974;20:148-151.

2. Hintze RE, Adler A, Veltzke W, Abou-Rebyeh H. Endoscopic access to the papilla of Vater for endoscopic retrograde cholangiopancreatography in patients with billroth II or Roux-en-Y gastrojejunostomy. Endoscopy 1997;29:69-73.

3. Wright BE, Cass OW, Freeman ML. ERCP in patients with long-limb Roux-en-Y gastrojejunostomy and intact papilla. Gastrointest Endosc
2002:56:225-232.

4. Lobo DN, Balfour TW, Iftikhar SY. Periampullary diverticula: consequences of failed ERCP. Ann R Coll Surg Engl 1998;80:326-331.

5. Faylona JM, Qadir A, Chan AC, Lau JY, Chung SC. Small bowel perforations related to endoscopic retrograde cholangiopancreatography (ERCP) in patients with Billroth II gastrectomy. Endoscopy 1999;31:546549.

6. Bergman JJ, van Berkel AM, Bruno MJ, et al. A randomized trial of endoscopic balloon dilation and endoscopic sphincterotomy for removal of bile duct stones in patients with a prior Billroth II gastrectomy. Gastrointest Endosc 2001;53:19-26.

7. Gil S, de la Iglesia P, Verdú JF, de España F, Arenas J, Irurzun J. Effectiveness and safety of balloon dilation of the papilla and the use of an occlusion balloon for clearance of bile duct calculi. AJR Am J Roentgenol 2000;174:1455-1460.

8. García-García L, Lanciego C. Percutaneous treatment of biliary stones: sphincteroplasty and occlusion balloon for the clearance of bile duct calculi. AJR AM J Roentgenol 2004;182:663-670.

9. Han YM, Kwak HS, Jin GY, Lee SO, Chung GH. Treatment of malignant biliary obstruction with a PTFE-covered self-expandable nitinol stent. Korean J Radiol 2007;8:410-417.

10. Sato H, Kodama T, Takaaki J, et al. Endoscopic papillary balloon dilatation may preserve sphincter of Oddi function after common bile duct stone management: evaluation from the viewpoint of endoscopic manometry. Gut 1997;41:541-544.

11. Mondet AF. Technic of blood extraction of calculi in residual lithasis of the choledochus. Bol Trab Soc Cir B Aires 1962;46:278-290.

12. Perez MR, Oleaga JA, Freiman DB, McLean GL, Ring EJ. Removal of a distal common bile duct stone through percutaneous transhepatic catheterization. Arch Surg 1979;114:107-109.

13. Dotter CT, Bilbao MK, Katon RM. Percutaneous transhepatic gallstone removal by needle tract. Radiology 1979;133:242-243.

14. Choi SA, Han YM, Jin GY, Lee SO, Yu HC. Effectiveness of percutaneous biliary stone removal as primary treatment in cases with difficulties in the use of an endoscopy. J Korean Soc Radiol 2014;70:225-231.

15. García-Vila JH, Redondo-Ibáñez M, Díaz-Ramón C. Balloon sphincteroplasty and transpapillary elimination of bile duct stones: 10 years' experience. AJR Am J Roentgenol 2004;182:1451-1458. 